Article

\title{
Characterization of the Microbial Communities in Rumen Fluid Inoculated Reactors for the Biogas Digestion of Wheat Straw
}

\author{
$\mathrm{Ke} \mathrm{Li}^{1,2}$, Haoran Zhu ${ }^{1}$, Yajie Zhang ${ }^{1}$ and Hongxun Zhang ${ }^{1, *}$ \\ 1 College of Resources and Environment, University of Chinese Academy of Sciences, Beijing 101408, China; \\ like210@mails.ucas.ac.cn (K.L.); zhr.c@foxmail.com (H.Z.); zhuoanyouzhuan@163.com (Y.Z.) \\ 2 Water Affairs Research Institute, North China University of Water Resources and Electric Power, \\ Zhengzhou 450045, China \\ * Correspondence: hxzhang@ucas.ac.cn; Tel.: +86-10-6967-2955
}

Academic Editor: Emmanuel K. Ackom

Received: 17 December 2016; Accepted: 4 February 2017; Published: 10 February 2017

\begin{abstract}
The present study investigated the effect of rumen fluid (RF) concentration on the methane production through anaerobic digestion of wheat straw in batch mode, and compared the microbial communities in RF and RF inoculated reactors by $16 \mathrm{~S}$ rRNA genes sequencing. Six levels of RF concentration including $1 \%, 5 \%, 10 \%, 15 \%, 20 \%$ and $25 \%(v / v)$ were used in reactors R1, R5, R10, R15, R20 and R25 respectively. The results revealed that lower than or equal to $5 \%$ RF concentrations resulted in reactor acidification and low methane production. The highest methane yield of $106 \mathrm{~mL} \cdot \mathrm{CH}_{4} \cdot \mathrm{g} \cdot \mathrm{VS}^{-1}$ was achieved in R10, whereas higher RF concentrations than $10 \%$ could not improve the methane production significantly. Methanosarcina barkeri was abundant in the well-working reactors, and Methanobacterium was dominant in the poor-working reactors, implying the archaeal communities in reactors had changed greatly from the Methanobrevibacter-dominated RF. Although the relative abundance of Clostridium and Ruminococcus were greatly different between RF and reactors, the Bacteroidetes and Firmicutes communities were dominant in all the tested samples. The results indicated that the in vitro anaerobic conditions had altered the rumen methanogenic communities significantly and the facultative acetoclastic Methanosarcina was important for the methane production in the RF seeded reactors.
\end{abstract}

Keywords: anaerobic digestion; inoculum concentration; lignocellulose; methanogenesis; rumen fluid

\section{Introduction}

Lignocellulosic materials include a large fraction of municipal solid waste, crop residues, animal manures, woodlot arisings, forest residues, and/or dedicated energy crops [1]. Because they are abundant in renewable biomass with low treatment costs, they are broadly employed for methane production in recent years [2]. Anaerobic digestion of lignocellulosic biomass for methane production is usually used for its simultaneous recovery of methane as a renewable energy source and residual solids or liquid as green fertilizers [3,4]. However, lignocellulose solubilization is the rate-limiting step for methane production during anaerobic digestion [5,6], and microorganisms with high efficiency of lignocellulose degradation are highly important for improving the performance of anaerobic digestion.

A complex microbial community that can cooperatively and completely digest the lignocellulosic biomass has been universally found in the rumens of ruminant animals $[7,8]$. Fibrobacter succinogenes, Ruminococcus albus, and Ruminococcus flavefaciens are the main fibrolytic microorganisms in the rumens [9,10], and Butyrivibrio fibrisolvens and Prevotella sp. are found to produce xylanases [9]. The non-fibrolytic bacteria, such as Succinivibrio dextrinosolvens, Selenomonas ruminantium, and 
Anaerovibrio lipolytica could facilitate plant fiber digestion in the rumen [10]. Additionally, rumen methane production, which is mainly due to the hydrogenotrophic Methanobrevibacter, is also a subject of concern for its contribution to the greenhouse gas increment [11,12]. In rumen, the aceticlastic pathway was not important with low numbers of Methanosarcina retrieved $[13,14]$. Recent years, methylotrophic Methanomassiliicocales, which was one of the most important methanogens populations [15,16], was found to be abundant in some rumens [17].

It is believed that the rumen microorganisms mentioned above would guarantee the good performance of RF inoculated reactors, and the potential application of rumen cultures for the anaerobic digestion of lignocellulosic biomass had been investigated in previous studies [5,6,18-21]. Reactors seeded with rumen microorganisms showed higher rates of cellulose solubilization than other inocula $[5,6]$. The effect of different RF concentration on the in vitro degradation of cellulose was studied, and the hydrolysis rates of cellulose were revealed to decrease with the decrease of RF concentrations [5]. Although RF has been used for the digestion of lignocellulosic biomass [20,22], the RF concentration and the experiment procedures cannot be comparable with each other. Thus, the appropriate RF concentration for in vitro methane production is still unknown. Additionally, the inoculation of natural microbial communities in the anaerobic digestion process would result in the changes of community structure, and therefore the in vitro rumen experiments could not be representative of the performance of rumen microorganisms under in vivo conditions [5,22]. Therefore, it is necessary to investigate both the microbial communities in RF and RF seeded reactors, especially in the reactors inoculated with different $\mathrm{RF}$ concentration. Experiments were performed using different $\mathrm{RF}$ concentrations for the wheat straw anaerobic digestion to (1) explore the appropriate RF concentration for methane production and (2) characterize the bacterial and archaeal communities in RF and RF seeded reactors.

\section{Materials and Methods}

\subsection{Substrate and Inoculum}

Wheat straw was collected from Xichuan in Nanyang, China. The sun-dried straws were ground to pass a 60 -mesh sieve $(250-\mu \mathrm{m}$ pore size), and were then used as the substrate for anaerobic digestion. Total solids (TS) and volatile solids (VS) of the milled straws were $95.0 \% \pm 1.4 \%$ and $85.3 \% \pm 1.8 \%$ respectively.

The rumen contents were obtained from an adult cow fed with grass silage-based diets after it was killed at Yulin abattoir in China. Sterile bottles were used for the collection of the rumen contents and then sealed using gas-impermeable rubber stoppers. The bottles containing samples were kept on ice and transported back to laboratory, where the rumen contents were squeezed through four layers of cheesecloth with the protection of $\mathrm{N}_{2}$ to remove coarse solids. Approximately $20 \mathrm{~mL}$ of rumen fluid (RF) was stored at $-20^{\circ} \mathrm{C}$ for DNA extraction, and the remaining RF was used as inoculum.

\subsection{Reactors}

Batch digestions were carried out in $100 \mathrm{~mL}$ ( $60 \mathrm{~mL}$ working volume) serum vials at $39 \pm 1{ }^{\circ} \mathrm{C}$ for 40 days with RF as the inoculum, and all the serum bottles were filled with high purity nitrogen gas. The digestion medium was the basal mineral salts solution $[5,23]$, with additional wheat straw $\left(20 \mathrm{~g} \cdot \mathrm{L}^{-1}\right)$ as the sole carbon source. The $\mathrm{pH}$ of the combined media and inoculum at the start of the experiments was between 7.0 and 7.8.

All batch reactors containing RF were prepared at concentrations of $1 \%, 5 \%, 10 \%, 15 \%, 20 \%$, and $25 \%(v / v)$ for the reactors R1, R5, R10, R15, R20, and R25 respectively. In reactors that contained less than $10 \% \mathrm{RF}$, the inoculum was made up to $10 \%$ with sterilized RF (the RF was centrifuged at $14,000 \times g$ for $30 \mathrm{~min}$ ) (e.g., the $5 \% \mathrm{RF}$ contained $3 \mathrm{~mL}$ active $\mathrm{RF}$ and $3 \mathrm{~mL}$ sterilized $\mathrm{RF}$ ). In reactors that contained more than $10 \%$ rumen inoculum, the inoculum was prepared by removing certain volume of supernatant after the active RF was centrifuged at $14,000 \times g$ for $30 \mathrm{~min}$ (e.g., $25 \% \mathrm{RF}$ was 
prepared by removing of $9 \mathrm{~mL}$ of supernatant out of $15 \mathrm{~mL}$ of centrifuged RF). All the treatments (batch reactors with different concentrations of RF) were duplicated, and the digestion experiment was repeated three times.

\subsection{Analytical Methods}

The biogas generated was measured by downward displacement of water. Biogas samples were analyzed for $\mathrm{CO}_{2}$ and $\mathrm{CH}_{4}$ concentration with an Agilent 7890A gas chromatograph (Agilent Technologies, Santa Clara, CA, USA), with helium as the gas carrier, equipped with a Porapak Q column ( $2 \mathrm{~m}$ length, $3 \mathrm{~mm}$ ID) and a thermal conductivity detector (TCD). The temperature of the injector, column oven and detector were $120{ }^{\circ} \mathrm{C}, 120^{\circ} \mathrm{C}$ and $160{ }^{\circ} \mathrm{C}$ respectively. Volatile fatty acids (VFAs) including acetate, propionate and formate were measured by Shimadzu HPLC system (Shimadzu, Kyoto, Japan) equipped with TSKgel ODS-100V, C18 reverse phase colum $(4.6 \mathrm{~mm} \times 250 \mathrm{~mm}$ ID, 5.0 $\mu \mathrm{m}$ particle size; Tokoh, Tokyo, Japan). The mobile phase for separation was $0.1 \%$ phosphoric acid. The solvent was maintained at a flow rate of $1.0 \mathrm{~mL} \cdot \mathrm{min}^{-1}$. UV detection was performed simultaneously at wavelengths of $210 \mathrm{~nm}$. Standard curves were prepared for the measurement of $\mathrm{CH}_{4}$, acetate, propionate, and formate in this study (the data were not shown).

TS and VS contents were analyzed according to the Standard Methods for the Examination of Water and Wastewater [24]. The $\mathrm{pH}$ was measured by a portable $\mathrm{pH}$ meter (Hach, Loveland, CO, USA).

\subsection{DNA Extraction, PCR Amplification, SEQUENCING, and Sequences Analysis}

For DNA extraction, triplicate $0.5-\mathrm{mL}$ original RF and the digested effluent on day 40 were taken. DNA Extraction from 0.5-mL sample was performed using FastDNA SPIN kit for soil (Bio 101 Systems, Carlsbad, CA, USA) according to the manufacturer's instructions.

To explore the bacterial and archaeal composition, $16 \mathrm{~S}$ rRNA gene clone libraries were constructed. Primer pairs BAC8F/926R [25] and AR109F/915R [26] were used to amplify the bacterial and archaeal $16 \mathrm{~S}$ rRNA genes respectively. PCR amplifications were performed with an iCycler thermal cycler (Bio-Rad, Richmond, CA, USA), and the amplification conditions were as follows: denaturing step of $94{ }^{\circ} \mathrm{C}$ for $4 \mathrm{~min} ; 30$ cycles of denaturation at $94{ }^{\circ} \mathrm{C}$ for $45 \mathrm{~s}$, annealing at $57{ }^{\circ} \mathrm{C}$ (for bacteria) or $52{ }^{\circ} \mathrm{C}$ (for archaea) for $45 \mathrm{~s}$, extension at $72{ }^{\circ} \mathrm{C}$ for $60 \mathrm{~s}$; the final step was followed by post extension at $72{ }^{\circ} \mathrm{C}$ for $10 \mathrm{~min}$. The PCR products were purified using a GeneJET PCR Purification Kit (Thermo, Waltham, MA, USA), and then used for clone libraries constructed directly in accordance with the procedure used previously [27]. The clones were selected for colony PCR using universal M13 primers [28] and the positive clones were then sequenced with an Applied Biosystems 3730 DNA analyzer (Applied Biosystems, Carlsbad, CA, USA).

The chimeric sequences were checked by Mallard software [29]. Then the operational taxonomic unit (OTU) numbers were determined from the remaining sequences using Mothur by defining the sequences sharing $97 \%$ similarity as 1 OTU [30]. The sequences and OTUs classification were conducted using Mothur with a naïve Bayesian approach at a confidence threshold of 70\% [30]. Shannon diversity indices $(\mathrm{H})$, species richness (Chao 1), and coverage were also calculated using Mothur [30]. The Libshuff [31,32] and Venn diagram in Mothur were used to compare the community structures in different samples. Representing sequences of archaeal OTUs were searched against the GenBank database by using the BLASTn program to determine the closest matches. Then phylogenetic trees were constructed using Mega (version 5.0, Arizona State University, Tempe, AZ, USA, 2011) [33] by the neighbor-joining algorithm, and the Jukes-Cantor distance estimation method with bootstrap analyses for 1000 replicates was performed.

Sequences of unique phylotype obtained in this study were deposited in GenBank under accession numbers KT024822-KT024936 (bacterial 16S rRNA gene) and KT024937-KT024951 (Archaeal 16S rRNA gene). 


\section{Results}

\subsection{The Performance of Anaerobic Reactors}

The experimental bioreactors were run in batch mode for 40 days. The methane yields of R10, $\mathrm{R} 15, \mathrm{R} 20$ and R25 ranged from $96 \mathrm{~mL} \cdot \mathrm{g} \cdot \mathrm{VS}^{-1}$ to $106 \mathrm{~mL} \cdot \mathrm{g} \cdot \mathrm{VS}^{-1}$ with $\mathrm{R} 10$ being the highest yields (Figure 1a). The results of accumulative methane and biogas yield showed that the rates of methane and biogas production of R10, R15, R20, and R25 were not greatly different from each other during the 40-day anaerobic digestion (Figure $1 \mathrm{~b}, \mathrm{c}$ ), whereas the rates of methane and biogas production of R1 and R5 were much lower than that of R10, R15, R20, and R25 during all the digestion times (Figure $1 \mathrm{~b}, \mathrm{c}$ ). R1 and $\mathrm{R} 5$ achieved $5 \mathrm{~mL} \cdot \mathrm{CH}_{4} \cdot \mathrm{g} \cdot \mathrm{VS}^{-1}$ and $47 \mathrm{~mL} \cdot \mathrm{CH}_{4} \cdot \mathrm{g} \cdot \mathrm{VS}^{-1}$ and the corresponding biogas yields were $95 \mathrm{~mL} \cdot \mathrm{g} \cdot \mathrm{VS}^{-1}$ and $172 \mathrm{~mL} \cdot \mathrm{g} \cdot \mathrm{VS}^{-1}$ respectively, much lower than that of R10, R15, R20, and R25 (Figure 1a). On days 0-10, almost no methane was produced in R1 and R5 (Figure 1b), and the methane content was $0 \%$ in these reactors (Figure 1d). However, the methane content in other reactors began to increase on day 3 and fluctuated between $16 \%$ and $83 \%$ during the anaerobic digestion (Figure 1d).

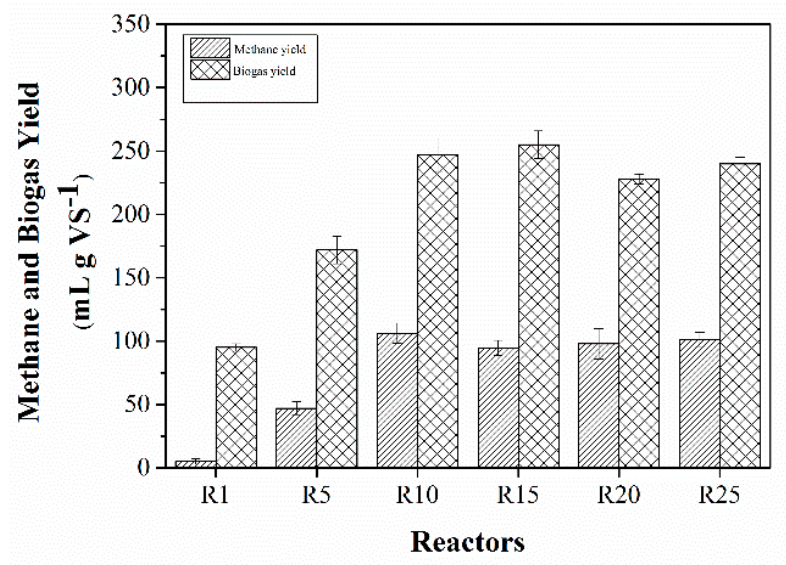

(a)

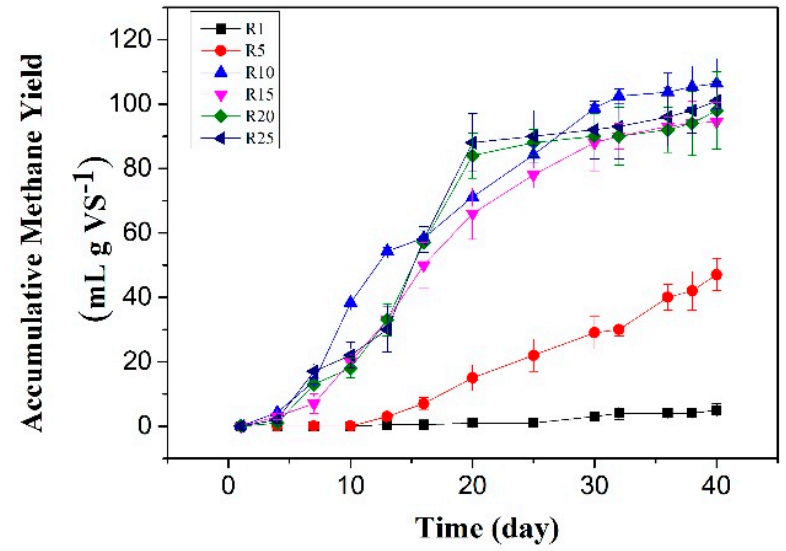

(b)

Figure 1. Cont. 


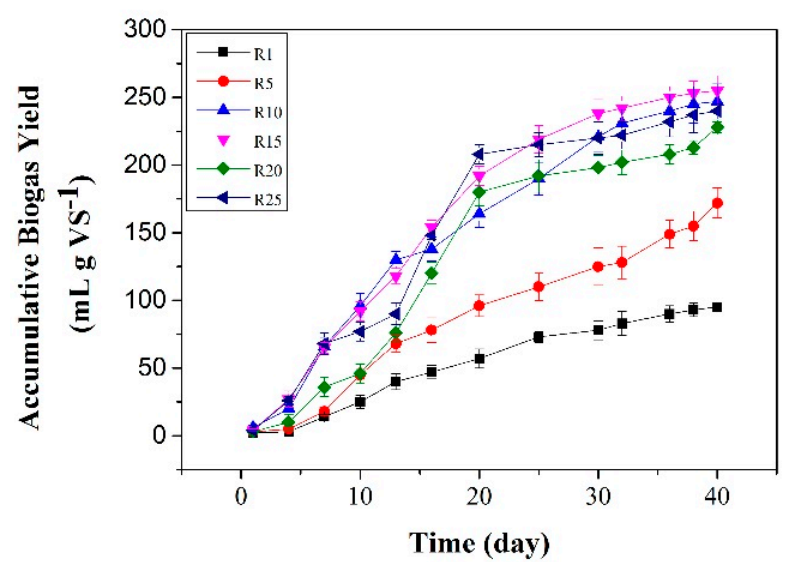

(c)

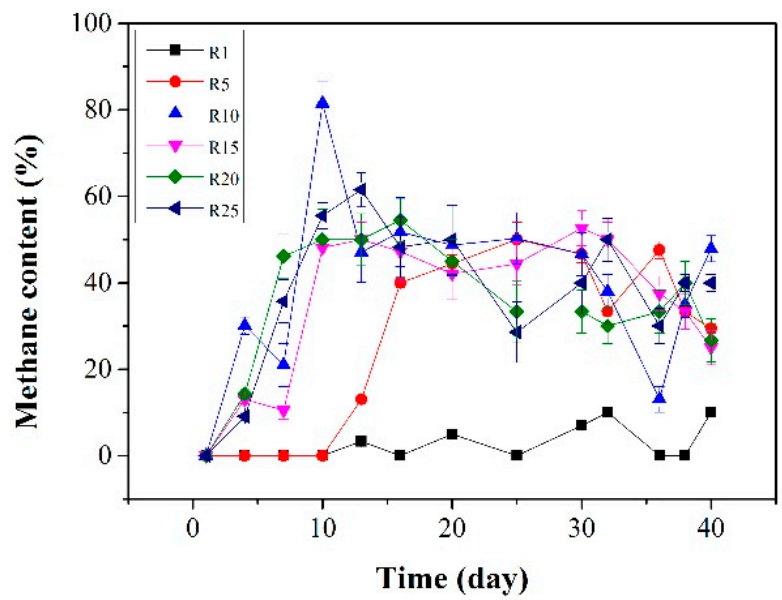

(d)

Figure 1. Characteristics of the anaerobic reactors for methane and biogas yields. (a) The methane and biogas yield; (b) Accumulative methane yield; (c) Accumulatice biogas yield; (d) Methane content. Data represent the means of six replicates, with error bars representing the standard deviation of the mean.

After 40 days of digestion, the TS and VS reduction of the reactors were $30.0 \%-38.4 \%$ and $33.0 \%-42.4 \%$ respectively (Table 1 ). The final $\mathrm{pH}$ values were below 5.50 in $\mathrm{R} 1$ and $\mathrm{R} 5$, and between 6.09 and 7.95 in the other reactors (Table 1). Volatile fatty acids (VFAs) mainly containing formate, acetate, and propionate were detected (Figure 2). No great differences were observed in formate concentrations among different reactors, which ranged from $0.7 \mathrm{mM}$ to $1.2 \mathrm{mM}$ in all the reactors (Figure 2). The acetate concentration in R1 and R5 was higher than $58.4 \mathrm{mM}$, whereas it obviously decreased in R10, R15, R20, and R25 (Figure 2). The propionate concentration in R1, R5, R10, and R15 ranged from $10.6 \mathrm{mM}$ to $13.8 \mathrm{mM}$, while it was slightly higher in R20 and R25 (Figure 2). At the start time of the anaerobic digestion, the COD of the batch reactors ranged from $4207 \mathrm{mg} \cdot \mathrm{L}^{-1}$ to $4575 \mathrm{mg} \cdot \mathrm{L}^{-1}$, and on day 40 the COD was slightly higher than the start time (Table A1 in Appendix A). 
Table 1. The TS reduction, VS reduction, and $\mathrm{pH}$ of the anaerobic reactors.

\begin{tabular}{|c|c|c|c|}
\hline Reactors & TS Reduction $^{\text {a }}$ & VS Reduction $^{a}$ & $\mathrm{pH}$ \\
\hline R1 & $36.2 \% \pm 2.2 \%$ & $39.5 \% \pm 3.3 \%$ & $5.45 \pm 0.05$ \\
\hline $\mathrm{R} 5$ & $35.7 \% \pm 2.5 \%$ & $38.0 \% \pm 0.5 \%$ & $5.40 \pm 0.02$ \\
\hline R10 & $38.4 \% \pm 2.9 \%$ & $42.4 \% \pm 0.6 \%$ & $7.32 \pm 0.83$ \\
\hline R15 & $34.2 \% \pm 0.6 \%$ & $37.6 \% \pm 1.0 \%$ & $6.62 \pm 0.53$ \\
\hline $\mathrm{R} 20$ & $30.0 \% \pm 0.3 \%$ & $33.0 \% \pm 0.7 \%$ & $6.68 \pm 0.35$ \\
\hline $\mathrm{R} 25$ & $35.4 \% \pm 1.2 \%$ & $35.9 \% \pm 1.3 \%$ & $7.72 \pm 0.23$ \\
\hline
\end{tabular}

TS total solids, VS volatile solids; ${ }^{\text {a }}$ Mean \pm SD of $n=6$.

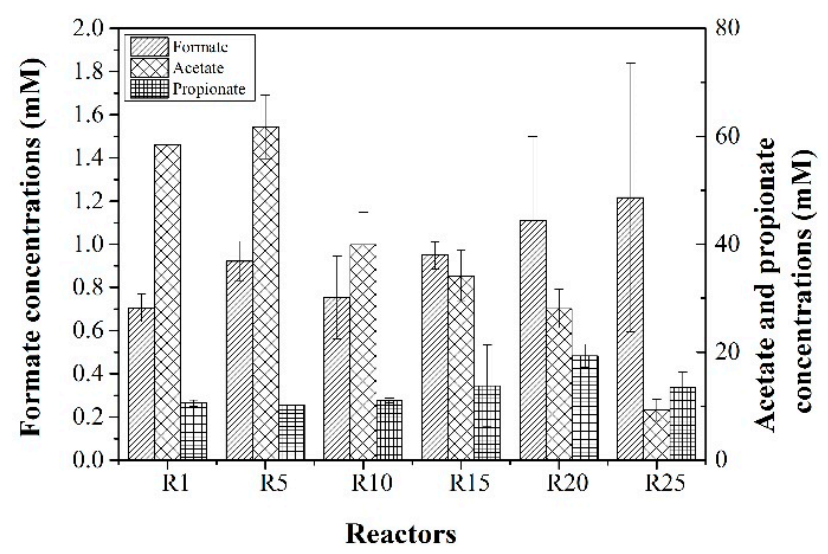

Figure 2. The formate, acetate, and propionate concentrations at the end of the 40-day anaerobic digestion. Data represent the means of six replicates, with error bars representing the standard deviation of the mean.

\subsection{Microbial Community Structure}

The bacterial and archaeal 16S rRNA gene clone libraries were established from RF and three batch reactors (R1, R10, and R25). A total of 311 bacterial sequences and 185 archaeal sequences were derived from the four samples (Table 2). Analysis of the coverage (Table 2) showed that bacterial libraries could not account for all the bacterial species. However, the coverage of archaeal libraries surpassed $90 \%$ (even surpassed $97 \%$ in anaerobic reactors), suggesting almost all of the archaeal sequences had been sampled (Table 2). R1 had the lowest microbial diversity with Shannon diversity index of 2.16 and 0.46 in bacterial and archaeal libraries respectively, whereas both the bacterial and archaeal diversities were highest in R25 among the three reactors (Table 2).

Table 2. Biodiversity indices and statistics among the $16 \mathrm{~S}$ rRNA gene clone libraries.

\begin{tabular}{ccccc}
\hline & Clones & OTUs $^{\mathbf{a}}$ & Coverage (\%) $^{\mathbf{a}}$ & Shanon Diversity $^{\mathbf{a}}$ \\
\hline Bacteria & & & & \\
RF & 72 & 49 & 52 & $3.77(3.59,3.95)$ \\
R1 & 82 & 26 & 78 & $2.16(1.81,2.51)$ \\
R10 & 78 & 31 & 78 & $2.95(2.70,3.21)$ \\
R25 & 79 & 34 & 72 & $3.20(2.97,3.41)$ \\
\hline Archaea & & & & \\
RF & 47 & 7 & 93 & $1.23(0.94,1.52)$ \\
R1 & 64 & 4 & 98 & $0.46(0.21,0.70)$ \\
R10 & 37 & 3 & 98 & $0.77(0.62,0.92)$ \\
R25 & 37 & 5 & 97 & $1.44(1.19,1.69)$ \\
\hline
\end{tabular}

${ }^{a}$ The values were calculated based on a $97 \%$ similarity threshold. 
The phylogenetic analysis showed that the microbial communities were significantly different among all the samples (Lishuff analysis with all $p<0.0001$ ). The overlaps of the bacterial and archaeal OTUs among the four samples were shown by venn diagrams in Figure 3, in which no bacterial or archaeal OTUs were shared among all the four samples. It was observed that no archaeal OTUs derived from RF were detected from reactor samples and only one RF bacterial OTU was detected from R1 and R25 (Figure 3). However, there were five bacterial OTUs and two archaeal OTUs shared among all the reactor samples (Figure 3).

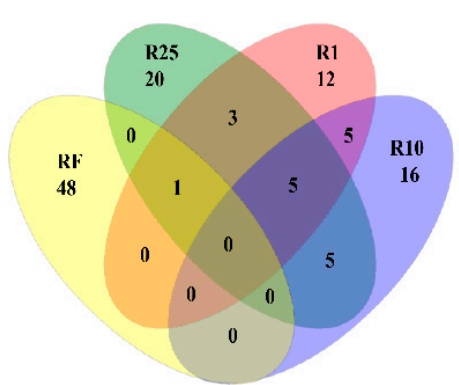

(a)

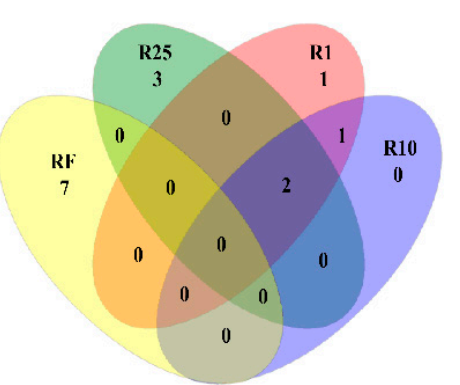

(b)

Figure 3. Venn diagrams of shared OTUs among RF, R1, R10, and R25 in (a) bacterial and (b) archaeal libraries, respectively.

\subsubsection{Bacterial Community Composition}

The obtained bacterial sequences of the four libraries fell into 10 phyla (Figure 4). The phyla Bacteroidetes and Firmicutes were dominant all the samples, composing 37.2\%-54.9\% (RF, $45.8 \%$; R1; 54.9\%; R10, 37.2\%; R25 38.0\%) and 26.6\%-47.4\% (RF, 37.5\%; R1; 40.3\%; R10, 47.4\%; R25 26.6\%) of the total bacterial sequences, respectively (Figure 4). The order Bacteroidales in Bacteroidetes and the order Clostridiales in Firmicutes were the most abundant taxa. The genera detected from the phylum Bacteroidetes included Bacteroides, Barnesiella, Dysgonomonas, Parabacteroides, Prevotella, RC9, and vadin $B C 27$, all of which were affiliated to the order Bacteroidales. The genus Bacteroides was detected from all the four samples and was the most abundant genus in R1 and R10 (representing $52.44 \%$ and $20.51 \%$ in R1 and R10 respectively), whereas it only composed less than $6 \%$ of the bacterial communities in RF and R25 (Table 3). The genera detected from the order Clostridiales including Clostridium, Ruminococcus, Anaerobacter, Blautia, Robinsoniella, Syntrophococcus, Acetanaerobacterium, Ethanoligenens, Oscillibacter, and Subdoligranulum, accounted for $83.3 \%$ of the total genera in Firmicutes. However, the relative abundance of Clostridiales genera varied greatly among the four samples, e.g., genus Clostridium was not detected from RF but was abundant in the three reactors, whereas genus Ruminococcus was not detected from the reactors but was abundant in RF. Phylum Proteobacteria was the third most abundant phylum, and genus Escherichia in Proteobacteria was detected from all the reactors. In addition, Sphingomonas, Comamonas, Succinivibrio, and Citrobacter in Proteobacteria were also detected in this study. Other phyla such as Fibrobacteres, Spirochaetes, Synergistetes, Actinobacteria, Verrucomicrobia, Tenericutes, and Lentisphaerae were detected in some of the samples and only in minor proportions (Figure 4). 


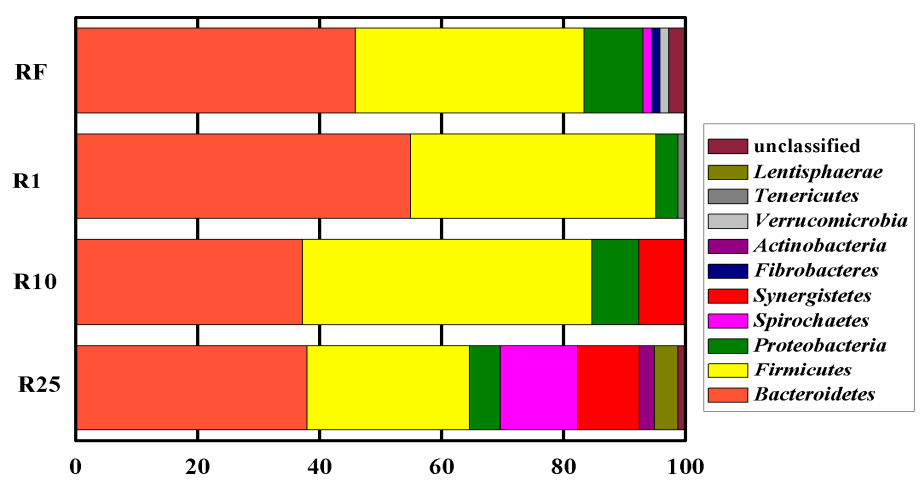

Relative abundance (\%)

Figure 4. Relative abundance of sequences evaluated at phylum level to the total sequences in each bacterial library (\%).

Table 3. The identified genera and their relative abundance in RF, R1, R10, and R25 respectively.

\begin{tabular}{|c|c|c|c|c|c|}
\hline & \multirow[b]{2}{*}{ Genus } & \multicolumn{4}{|c|}{ The Relative Abundance (\%) } \\
\hline & & RF & R1 & R10 & R25 \\
\hline \multicolumn{6}{|l|}{ Bacteroidetes } \\
\hline \multirow{7}{*}{ Bacteroidales } & Bacteroides & 5.56 & 52.44 & 20.51 & 3.80 \\
\hline & Barnesiella & 1.39 & NA & NA & NA \\
\hline & Dysgonomonas & NA & 1.22 & 6.41 & NA \\
\hline & Parabacteroides & NA & NA & 5.13 & NA \\
\hline & Prevotella & 4.17 & NA & 5.13 & 5.06 \\
\hline & RC9 & 5.56 & NA & NA & 7.59 \\
\hline & vadin $B C 27$ & NA & NA & NA & 1.27 \\
\hline \multicolumn{6}{|l|}{ Firmicutes } \\
\hline \multirow{2}{*}{ Bacillales } & Caryophanon & NA & 1.22 & NA & NA \\
\hline & Lysinibacillus & NA & 1.22 & NA & 10.13 \\
\hline \multirow{10}{*}{ Clostridiales } & Anaerobacter & NA & 1.22 & 1.28 & NA \\
\hline & Clostridium & NA & 4.88 & 3.85 & 2.53 \\
\hline & Blautia & NA & NA & NA & 1.27 \\
\hline & Robinsoniella & 1.39 & NA & NA & NA \\
\hline & Syntrophococcus & NA & NA & 1.28 & NA \\
\hline & Acetanaerobacterium & NA & NA & NA & 1.27 \\
\hline & Ethanoligenens & NA & 1.22 & 1.28 & NA \\
\hline & Oscillibacter & 1.39 & NA & 1.28 & NA \\
\hline & Ruminococcus & 4.17 & NA & NA & NA \\
\hline & Subdoligranulum & NA & NA & 1.28 & NA \\
\hline \multicolumn{6}{|l|}{ Tenericutes } \\
\hline $\begin{array}{c}\text { Anaeroplasmatales } \\
\text { Lentisphaerae }\end{array}$ & Anaeroplasma & NA & 1.22 & NA & NA \\
\hline $\begin{array}{c}\text { Victivallales } \\
\text { Alnhroterian }\end{array}$ & Victivallis & NA & NA & NA & 3.80 \\
\hline $\begin{array}{l}\text { Alphaproteobacteria } \\
\text { Sphingomonadales }\end{array}$ & Sphingomonas & NA & NA & NA & 1.27 \\
\hline Burkholderiales & Comamonas & NA & 1.22 & NA & NA \\
\hline \multicolumn{6}{|l|}{ Gammaproteobacteria } \\
\hline Aeromonadales & Succinivibrio & 2.78 & NA & NA & NA \\
\hline \multirow{2}{*}{ Enterobacteriales } & Citrobacter & NA & 1.22 & NA & NA \\
\hline & Escherichia & NA & 1.22 & 6.41 & 2.53 \\
\hline \multicolumn{6}{|l|}{ Spirochaetes } \\
\hline Spirochaetales & Spirochaeta & NA & NA & NA & 12.66 \\
\hline Synergistetes & & & & & \\
\hline Synergistales & Pyramidobacter & NA & NA & 5.13 & 7.59 \\
\hline
\end{tabular}

NA: the genus was not found in that sample. 


\subsubsection{Archaeal Community Composition}

All of the obtained archaeal sequences in this study were affiliated to phylum Euryarchaeota, and these sequences could be assigned to five genera including Methanobrevibacter, Methanobacterium, Methanosacina, Methanoculleus, and Methanomassiliicoccus (Figure 5).
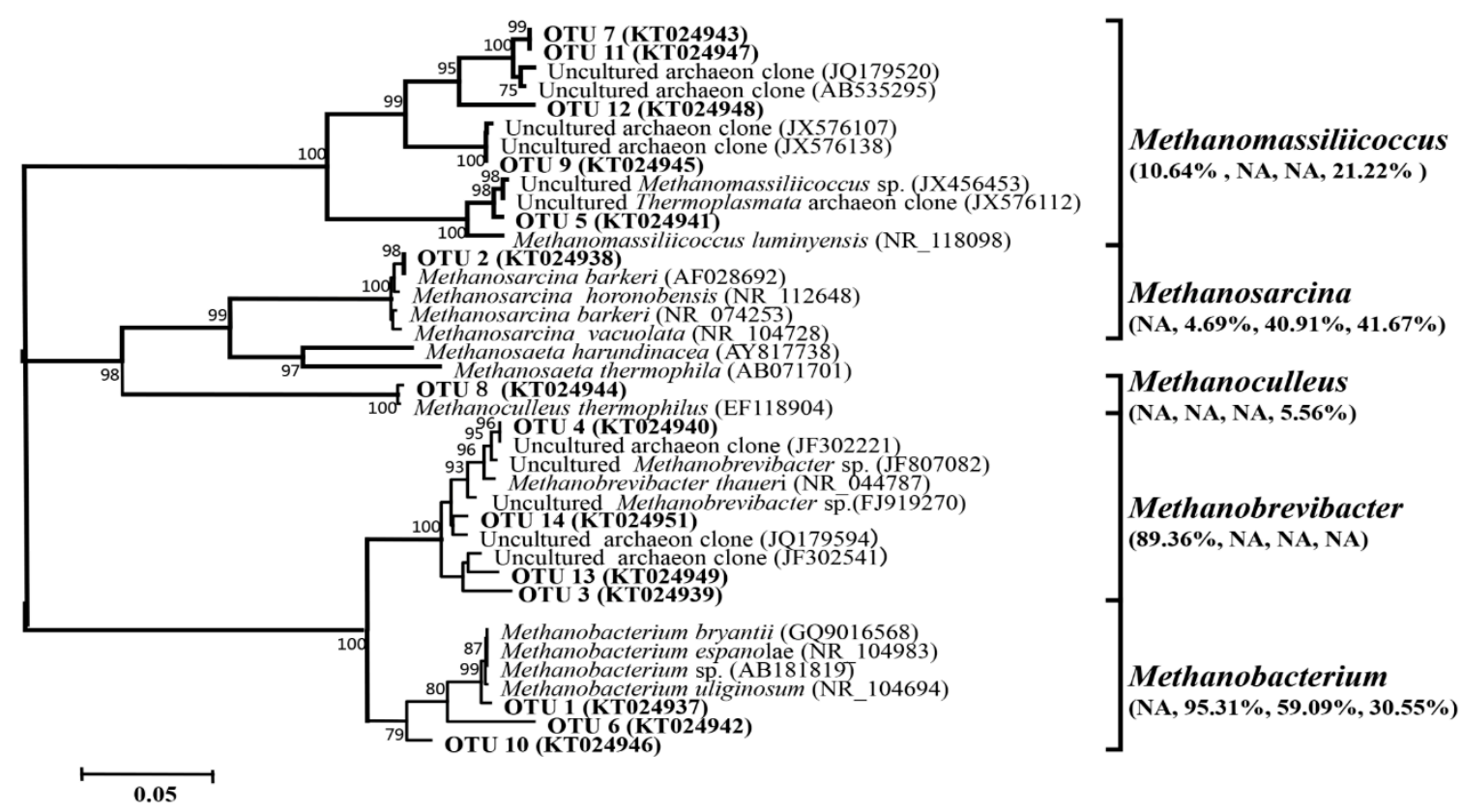

Figure 5. Archaeal 16S rRNA genes retrieved from RF, R1, R10, and R25. The phylogenetic relationship was determined by the neighbor-joining method and bootstrap values above $70 \%$ were shown at the nodes. The unique phylotypes identified in this study are highlighted (bold). The numbers in the bracket below the genus shown in the right of the figure represent the relative abundance in the libraries of RF, R1, R10, and R25 respectively, and NA indicates that the genus was not found in that sample.

Methanobrevibacter from the order Methanobacteriales was the most dominant genus in the RF archaeal clone library $(89.36 \%)$, whereas this genus was not derived from the anaerobic reactors. Sequences belonging to the genus Methanobacterium, another genus in the order Methanobacteriales, were dominant in R1 (95.31\%) and also abundant both in R10 (59.09\%) and R25 (30.55\%). The Methanosarcina sequence detected from the reactors showed 100\% similarity to Methanosarcina barkeri (AF028692), which could utilize both acetate and hydrogen [15]. Methanosarcina barkeri was the most abundant taxon in R25 (41.67\%) and was the second abundant taxon in R10 (40.91\%), whereas it was not detected from RF and only accounted for $4.69 \%$ of R1 archaeal community. Genus Methanoculleus representing $5.56 \%$ of R25 archaeal community was not derived from the other samples. In addition, methylotrophic methanogenic Methanomassiliicoccus was abundant in RF and R25 (10.64\% and 21.22\% in RF and R25, respectively). However, they were not detected from R1 and R10.

\section{Discussion}

Although it had been broadly believed that RF were attractive for the anaerobic digestion of lignocellulose $[4,6,18,20,34,35]$, little was known about how much RF was needed and how much methane would be yielded. In this study, a series of different concentrations of RF was used as inocula to investigate the appropriate RF concentrations for methane production. In R1 and R5, the methane and biogas yield were much lower than other rectors. In addition, the accumulation of acetate in R1 and $\mathrm{R} 5$ might result in the acidification in these reactors, which can deteriorate the anaerobic digestion process [36,37]. These physiochemical parameters of the reactors indicated that $1 \% \mathrm{RF}$ concentration could not start the anaerobic digestion successfully, and 5\% RF concentration could not achieve high 
methane production. However, the reactors inoculated with more than $10 \%$ RF worked well with neutral condition and achieved much higher methane production of $\left(96-106 \mathrm{~mL} \cdot \mathrm{g} \cdot \mathrm{VS}^{-1}\right)$.

The highest methane yield $\left(106 \mathrm{~mL} \cdot \mathrm{g} \cdot \mathrm{VS}^{-1}\right)$ was achieved in R10, which was a little lower than other anaerobic batch reactors with lignocellulose as the sole substrate [38,39]. The results implied that rumen microorganisms might not be the best inoculum for the in vitro biogas digestion of lignocellulose. The rumen microbial communities might have changed when they were inoculated in the reactors. Thus effluence of R1, R10, and R25, representing the poor-working, well-working, and well-working with high RF concentration reactors respectively, were integrated with RF to characterize the changes in rumen microbial communities.

\subsection{Different Methanogenesis between Bovine Rumen and Reactors}

Clear differences had been observed among methanogenic communities in RF and RF inoculated reactors. In bovine rumen, methanogens predominantly utilize $\mathrm{H}_{2}-\mathrm{CO}_{2}$ as substrates to produce methane [13], which was supported by the prevalence of hydrogenotrophic Methanobrevibacter in this study and previous studies $[11,12,40,41]$. In addition to the predominance of hydrogenotrophic methanogenesis, methylotrophic methanogenesis in bovine rumen might be undertaken by Methanomassiliicoccus, the growth of which could be enhanced by methylamine supplement [42].

However, in the well-working reactors R10 and R25, acetoclastic methanogenesis might be important, which was supported by the dominance of facultative acetoclastic Methanosarcina barkeri (Figure 5) and the lower acetate concentration compared to R1 (Figure 2). Acetoclastic methanogenesis accounting for over $70 \%$ methane production in anaerobic digesters [43,44], was considered as the major process in the biogas fermentation, and the dominance of the genus Methanosarcina had been found in various anaerobic digesters [45-47]. M. barkeri could utilize acetate, methanol, and $\mathrm{H}_{2}-\mathrm{CO}_{2}$ for methane production [44,48], which might enhance the competitive ability of Methanosarcina in anaerobic digesters [45]. Besides the importance of acetoclastic methanogenesis, hydrogenotrophic methanogenesis was also important in R10 and R25 with the abundant presence of Methanobacterium in both the reactors. In fact, most methanogens could undertake hydrogenotrophic methanogenesis $[44,49]$ and hydrogenotrophic methanogenesis in reactors had been favored in some conditions, such as high temperate and low biomass retention time [50]. However, there have been no general parameters standardized for the anaerobic process, which may favor the hydrogenotrophic methanogens or acetoclastic methanogenesis in the reactors $[49,50]$.

Unlike R10 and R25, the hydrogenotrophic genus Methanobacterium was dominant in the poor-working R1, much higher than that in R10 and R25. Among genus Methanobacterium, OTU 1 (Figure 5) showed 99\% similarity to Methanobacterium espanolae (NR_104983), which could survive slight acidic condition ( $\mathrm{pH}$ 5.0-7.5) [51], and the acid-tolerant characteristics may enhance the predominance of Methanobacterium espanolae in R1. It is inferred that the low inoculum concentration would lead to the reactor acidification which may inhibit the growth of Methanosarcina in R1 [44], and the low presence of acetoclastic Methanosarcina may in turn lead to the accumulation of acetate.

\subsection{Characteristics of Bacterial Community}

Although significant differences were observed among the four bacterial libraries based on the phylotype overlaps and Lishuff comparison, Bacteroidetes and Firmicutes were the most abundant phyla in all the four samples. The predominance of these two phyla has been characterized in various anaerobic digesters and rumens $[45,47,52,53]$.

Among the two dominant phyla, genera Bacteroides, Parabacteroides, Prevotella, Ruminococcus, and Clostridium have the potential of performing cellulose hydrolysis [8,54-56]. It should be noticed that the Ruminococcus, which was one of the representative cellulolytic bacteria in the rumen [8], was not detected in the anaerobic reactors, implying that they may not adaptive to the in vitro environment for straw degradation. The well-known cellulolytic genus Clostridium [47] was not detected in the rumen samples, but replaced genus Ruminococcus conducting the cellulose 
decomposing in the anaerobic reactors. Additionally, the Clostridium-related sequences in this work were affiliated to Clostridium cluster IV (Clostridium leptum), many of which are fibrolytic and butyrate producing microorganisms [57]. Some species in genus Bacteroides have the potential of endoglucanase (carboxymethylcellulase), cellulase, xylanase, and arylb-xylosidase activities [58,59], which may be the reason for their universal presence in lignocellulose-rich environments.

In addition, members of other phyla were also important for the anaerobic digestion process, e.g., the presence of Citrobacter and Escherichia in the reactors may be responsible for lignin degradation [60,61], and Spirochaeta is involved in cellulose degradation [54].

\section{Conclusions}

The RF concentrations have a significant effect on the anaerobic digestion of wheat straw and 10\% $(\mathrm{v} / \mathrm{v})$ or higher RF concentration is necessary for the anaerobic reactors. The microbial profiles showed that the great variety of lignocellulose-degrading bacteria in both RF and RF inoculated reactors were responsible for the lignocellulose degradation efficiency and these bacteria could produce enough methanogenic substrates such as acetate and $\mathrm{H}_{2}-\mathrm{CO}_{2}$. However, the rumen archaeal communities had altered greatly to adapt to the in vitro conditions. It is found that the high abundance of acetoclastic Methanosarcina was necessary for high methane production in RF inoculated reactors. In contrast, the low abundance of Methanosarcina may result in accumulative acidification in the reactors due to low acetate consumption efficiency.

Acknowledgments: This work was financially supported by a Knowledge Innovation Grant of Chinese Academy of Sciences (KZZD-EW-0901). The authors wish to thank Min Wei from Shandong University for providing assistance with methane and VFAs measurements.

Author Contributions: Ke Li performed the literature review, designed the experimental work, conducted most of the experiments, analyzed the data, and prepared the manuscript. Haoran Zhu measured the volume of biogas and the concentration of VFAs. Yajie Zhang contributed to the methane, TS, and VS measurement. Hongxun Zhang conceived the subject of the paper, provided the expertise on the research, and contributed to reviewing the manuscript.

Conflicts of Interest: The authors declare no conflict of interest.

\section{Appendix A}

Table A1. The COD concentration at the end of the experiments.

\begin{tabular}{cc}
\hline Reactors & COD $\left(\mathbf{m g} \cdot \mathbf{L}^{-\mathbf{1}}\right)$ \\
\hline R1 & $5758 \pm 273$ \\
R5 & $5082 \pm 336$ \\
R10 & $4591 \pm 95$ \\
R15 & $5389 \pm 764$ \\
R20 & $6049 \pm 351$ \\
R25 & $4729 \pm 56$ \\
\hline
\end{tabular}

\section{References}

1. Sims, R.E. Bioenergy Options for a Cleaner Environment in Developed and Developing Countries; Elsevier Science: London, UK, 2003.

2. Chen, X.; Zhang, Y.; Gu, Y.; Liu, Z.; Shen, Z.; Chu, H.; Zhou, X. Enhancing methane production from rice straw by extrusion pretreatment. Appl. Energy 2014, 122, 34-41. [CrossRef]

3. Song, Z.; Yang, G.; Liu, X.; Yan, Z.; Yuan, Y.; Liao, Y. Comparison of seven chemical pretreatments of corn straw for improving methane yield by anaerobic digestion. PLoS ONE 2014, 9, e101617. [CrossRef] [PubMed]

4. Yue, Z.B.; Li, W.W.; Yu, H.Q. Application of rumen microorganisms for anaerobic bioconversion of lignocellulosic biomass. Bioresour. Technol. 2013, 128, 738-744. [CrossRef] [PubMed] 
5. Jensen, P.D.; Hardin, M.T.; Clarke, W.P. Effect of biomass concentration and inoculum source on the rate of anaerobic cellulose solubilization. Bioresour. Technol. 2009, 100, 5219-5225. [CrossRef] [PubMed]

6. O'Sullivan, C.A.; Burrell, P.C.; Clarke, W.P.; Blackall, L.L. Comparison of cellulose solubilisation rates in rumen and landfill leachate inoculated reactors. Bioresour. Technol. 2006, 97, 2356-2363. [CrossRef] [PubMed]

7. Krause, D.O.; Nagaraja, T.G.; Wright, A.D.G.; Callaway, T.R. Board-invited review: Rumen microbiology: Leading the way in microbial ecology. J. Anim. Sci. 2013, 91, 331-341. [CrossRef] [PubMed]

8. Koike, S.; Yoshitani, S.; Kobayashi, Y.; Tanaka, K. Phylogenetic analysis of fiber-associated rumen bacterial community and pcr detection of uncultured bacteria. FEMS Microbiol. Lett. 2003, 229, 23-30. [CrossRef]

9. Krause, D.O.; Denman, S.E.; Mackie, R.I.; Morrison, M.; Rae, A.L.; Attwood, G.T.; McSweeney, C.S. Opportunities to improve fiber degradation in the rumen: Microbiology, ecology, and genomics. FEMS Microbiol. Rev. 2003, 27, 663-693. [CrossRef]

10. Koike, S.; Yabuki, H.; Kobayashi, Y. Interaction of rumen bacteria as assumed by colonization patterns on untreated and alkali-treated rice straw. Anim. Sci. J. 2014, 85, 524-531. [CrossRef] [PubMed]

11. Jeyanathan, J.; Kirs, M.; Ronimus, R.S.; Hoskin, S.O.; Janssen, P.H. Methanogen community structure in the rumens of farmed sheep, cattle and red deer fed different diets. FEMS Microbiol. Ecol. 2011, 76, 311-326. [CrossRef] [PubMed]

12. Popova, M.; Morgavi, D.P.; Martin, C. Methanogens and methanogenesis in the rumens and ceca of lambs fed two different high-grain-content diets. Appl. Environ. Microbiol. 2013, 79, 1777-1786. [CrossRef] [PubMed]

13. Morgavi, D.; Forano, E.; Martin, C.; Newbold, C. Microbial ecosystem and methanogenesis in ruminants. Animal 2010, 4, 1024-1036. [CrossRef] [PubMed]

14. Janssen, P.H.; Kirs, M. Structure of the archaeal community of the rumen. Appl. Environ. Microbiol. 2008, 74, 3619-3625. [CrossRef] [PubMed]

15. Paul, K.; Nonoh, J.O.; Mikulski, L.; Brune, A. “Methanoplasmatales”, thermoplasmatales-related archaea in termite guts and other environments, are the seventh order of methanogens. Appl. Environ. Microbiol. 2012, 78, 8245-8253. [CrossRef] [PubMed]

16. Söllinger, A.; Schwab, C.; Weinmaier, T.; Loy, A.; Tveit, A.T.; Schleper, C.; Urich, T. Phylogenetic and genomic analysis of methanomassiliicoccales in wetlands and animal intestinal tracts reveals clade-specific habitat preferences. FEMS Microbiol. Ecol. 2015, 229-246.

17. Seedorf, H.; Kittelmann, S.; Janssen, P.H. Few highly abundant operational taxonomic units dominate within rumen methanogenic archaeal species in new zealand sheep and cattle. Appl. Environ. Microbiol. 2015, 81, 986. [CrossRef] [PubMed]

18. Hu, Z.H.; Yu, H.Q. Anaerobic digestion of cattail by rumen cultures. Waste Manag. 2006, 26, 1222-1228. [CrossRef] [PubMed]

19. Yue, Z.B.; Yu, H.Q.; Harada, H.; Li, Y.Y. Optimization of anaerobic acidogenesis of an aquatic plant, canna indica., by rumen cultures. Water Res. 2007, 41, 2361-2370.

20. Sutherland, A.D.; Varela, J.C. Comparison of various microbial inocula for the efficient anaerobic digestion of laminaria hyperborea. BMC Biotechnol. 2014, 14, 7. [CrossRef] [PubMed]

21. Sawatdeenarunat, C.; Surendra, K.C.; Takara, D.; Oechsner, H.; Khanal, S.K. Anaerobic digestion of lignocellulosic biomass: Challenges and opportunities. Bioresour. Technol. 2015, 178, 178-186. [CrossRef] [PubMed]

22. Garcia, S.L.; Jangid, K.; Whitman, W.B.; Das, K.C. Transition of microbial communities during the adaption to anaerobic digestion of carrot waste. Bioresour. Technol. 2011, 102, 7249-7256. [CrossRef] [PubMed]

23. Coleman, G.; Taylor, A.; Baker, J. Rumen Entodiniomorphid Protozoa. In In Vitro Methods for Parasite Cultivation; Academic Press Ltd.: San Diego, CA, USA, 1987; pp. $29-51$.

24. Rice, E.W.; Bridgewater, L.; Association, A.P.H. Standard Methods for the Examination of Water and Wastewater; American Public Health Association: Washington, DC, USA, 2012.

25. Liu, W.T.; Marsh, T.L.; Cheng, H.; Forney, L.J. Characterization of microbial diversity by determining terminal restriction fragment length polymorphisms of genes encoding 16s rRNA. Appl. Environ. Microbiol. 1997, 63, 4516-4522. [PubMed]

26. Banning, N.; Brock, F.; Fry, J.C.; Parkes, R.J.; Hornibrook, E.R.; Weightman, A.J. Investigation of the methanogen population structure and activity in a brackish lake sediment. Environ. Microbiol. 2005, 7, 947-960. [CrossRef] [PubMed] 
27. Li, K.; Liu, R.; Zhang, H.; Yun, J. The diversity and abundance of bacteria and oxygenic phototrophs in saline biological desert crusts in xinjiang, northwest china. Microb. Ecol. 2013, 66, 40-48. [CrossRef] [PubMed]

28. Yong, L.; Li, L.F.; Chen, G.Q.; Ge, X.J. Development of ten microsatellite loci for gentiana crassicaulis (gentianaceae). Conserv. Genet. 2007, 8, 1499-1501.

29. Ashelford, K.E.; Chuzhanova, N.A.; Fry, J.C.; Jones, A.J.; Weightman, A.J. New screening software shows that most recent large 16s rrna gene clone libraries contain chimeras. Appl. Environ. Microbiol. 2006, 72, 5734-5741. [CrossRef] [PubMed]

30. Schloss, P.D.; Westcott, S.L.; Ryabin, T.; Hall, J.R.; Hartmann, M.; Hollister, E.B.; Lesniewski, R.A.; Oakley, B.B.; Parks, D.H.; Robinson, C.J. Introducing mothur: Open-source, platform-independent, community-supported software for describing and comparing microbial communities. Appl. Environ. Microbiol. 2009, 75, 7537-7541. [CrossRef] [PubMed]

31. Singleton, D.R.; Furlong, M.A.; Rathbun, S.L.; Whitman, W.B. Quantitative comparisons of 16s rrna gene sequence libraries from environmental samples. Appl. Environ. Microbiol. 2001, 67, 4374-4376. [CrossRef] [PubMed]

32. Schloss, P.D.; Larget, B.R.; Handelsman, J. Integration of microbial ecology and statistics: A test to compare gene libraries. Appl. Environ. Microbiol. 2004, 70, 5485-5492. [CrossRef] [PubMed]

33. Tamura, K.; Peterson, D.; Peterson, N.; Stecher, G.; Nei, M.; Kumar, S. Mega5: Molecular evolutionary genetics analysis using maximum likelihood, evolutionary distance, and maximum parsimony methods. Mol. Biol. Evol. 2011, 28, 2731-2739.

34. Ramin, M.; Lerose, D.; Tagliapietra, F.; Huhtanen, P. Comparison of rumen fluid inoculum vs. Faecal inoculum on predicted methane production using a fully automated in vitro gas production system. Livest. Sci. 2015, 181, 65-71.

35. Song, H.; Clarke, W.P.; Blackall, L.L. Concurrent microscopic observations and activity measurements of cellulose hydrolyzing and methanogenic populations during the batch anaerobic digestion of crystalline cellulose. Biotechnol. Bioeng. 2005, 91, 369-378. [CrossRef] [PubMed]

36. Azizi, A.; Kim, W.; Lee, J.H. Comparison of microbial communities during the anaerobic digestion of gracilaria under mesophilic and thermophilic conditions. World J. Microl. Biotechnol. 2016, 32, 158. [CrossRef] [PubMed]

37. Akuzawa, M.; Hori, T.; Haruta, S.; Ueno, Y.; Ishii, M.; Igarashi, Y. Distinctive responses of metabolically active microbiota to acidification in a thermophilic anaerobic digester. Microb. Ecol. 2011, 61, 595-605. [CrossRef] [PubMed]

38. Valdez-Vazquez, I.; Torres-Aguirre, G.J.; Molina, C.; Ruiz-Aguilar, G.M.L. Characterization of a lignocellulolytic consortium and methane production from untreated wheat straw: Dependence on nitrogen and phosphorous content. Bioresources 2016, 11, 4237-4251. [CrossRef]

39. Ferreira, L.C.; Nilsen, P.J.; Fdz-Polanco, F.; Perez-Elvira, S.I. Biomethane potential of wheat straw: Influence of particle size, water impregnation and thermal hydrolysis. Chem. Eng. J. 2014, 242, 254-259. [CrossRef]

40. Wright, A.D.G.; Auckland, C.H.; Lynn, D.H. Molecular diversity of methanogens in feedlot cattle from ontario and prince Edward Island, Canada. Appl. Environ. Microbiol. 2007, 73, 4206-4210. [CrossRef] [PubMed]

41. Wright, A.D.G.; Ma, X.; Obispo, N.E. Methanobrevibacter phylotypes are the dominant methanogens in sheep from venezuela. Microb. Ecol. 2008, 56, 390-394. [CrossRef] [PubMed]

42. Poulsen, M.; Schwab, C.; Jensen, B.B.; Engberg, R.M.; Spang, A.; Canibe, N.; Hojberg, O.; Milinovich, G.; Fragner, L.; Schleper, C.; et al. Methylotrophic methanogenic thermoplasmata implicated in reduced methane emissions from bovine rumen. Nat. Commun. 2013, 4. [CrossRef] [PubMed]

43. Valcke, D.; Verstraete, W. A practical method to estimate the acetoclastic methanogenic biomass in anaerobic sludges. J. Water Pollut. Control Fed. 1983, 1191-1195.

44. Liu, Y.; Whitman, W.B. Metabolic, phylogenetic, and ecological diversity of the methanogenic archaea. Ann. N.Y. Acad. Sci. 2008, 1125, 171-189. [CrossRef] [PubMed]

45. Sun, L.; Pope, P.B.; Eijsink, V.G.H.; Schnurer, A. Characterization of microbial community structure during continuous anaerobic digestion of straw and cow manure. Microb. Biotechnol. 2015, 8, 815-827. [CrossRef] [PubMed] 
46. Li, A.; Chu, Y.n.; Wang, X.; Ren, L.; Yu, J.; Liu, X.; Yan, J.; Zhang, L.; Wu, S.; Li, S. A pyrosequencing-based metagenomic study of methane-producing microbial community in solid-state biogas reactor. Biotechnol. Biofuels 2013, 6, 3. [CrossRef] [PubMed]

47. Ziganshin, A.M.; Liebetrau, J.; Pröter, J.; Kleinsteuber, S. Microbial community structure and dynamics during anaerobic digestion of various agricultural waste materials. Appl. Microbiol. Biot. 2013, 97, 5161-5174. [CrossRef] [PubMed]

48. Krzycki, J.; Kenealy, W.; DeNiro, M.; Zeikus, J. Stable carbon isotope fractionation by methanosarcina barkeri during methanogenesis from acetate, methanol, or carbon dioxide-hydrogen. Appl. Environ. Microbiol. 1987, 53, 2597-2599. [PubMed]

49. Thauer, R.K.; Kaster, A.K.; Seedorf, H.; Buckel, W.; Hedderich, R. Methanogenic archaea: Ecologically relevant differences in energy conservation. Nat. Rev. Microbiol. 2008, 6, 579-591. [CrossRef] [PubMed]

50. Demirel, B.; Scherer, P. The roles of acetotrophic and hydrogenotrophic methanogens during anaerobic conversion of biomass to methane: A review. Rev. Environ. Sci. Biotechnol. 2008, 7, 173-190. [CrossRef]

51. Bonin, A.S.; Boone, D.R. The Order Methanobacteriales. In The Prokaryotes; Springer: New York, NY, USA, 2006; pp. 231-243.

52. Kong, Y.; Teather, R.; Forster, R. Composition, spatial distribution, and diversity of the bacterial communities in the rumen of cows fed different forages. FEMS Microbiol. Ecol. 2010, 74, 612-622. [CrossRef] [PubMed]

53. Hanreich, A.; Schimpf, U.; Zakrzewski, M.; Schlüter, A.; Benndorf, D.; Heyer, R.; Rapp, E.; Pühler, A.; Reichl, U.; Klocke, M. Metagenome and metaproteome analyses of microbial communities in mesophilic biogas-producing anaerobic batch fermentations indicate concerted plant carbohydrate degradation. Syst. Appl. Microbiol. 2013, 36, 330-338. [CrossRef] [PubMed]

54. Cirne, D.; Lehtomäki, A.; Björnsson, L.; Blackall, L. Hydrolysis and microbial community analyses in two-stage anaerobic digestion of energy crops. J. Appl. Microbiol. 2007, 103, 516-527. [CrossRef] [PubMed]

55. Christy, P.M.; Gopinath, L.; Divya, D. A review on anaerobic decomposition and enhancement of biogas production through enzymes and microorganisms. Renew. Sustain. Energy Rev. 2014, 34, 167-173. [CrossRef]

56. Nelson, M.C.; Morrison, M.; Yu, Z. A meta-analysis of the microbial diversity observed in anaerobic digesters. Bioresour. Technol. 2011, 102, 3730-3739. [CrossRef]

57. Lay, C.; Sutren, M.; Rochet, V.; Saunier, K.; Doré, J.; Rigottiergois, L. Design and validation of 16s rrna probes to enumerate members of the clostridium leptum subgroup in human faecal microbiota. Environ. Microbiol. 2005, 7, 933-946. [CrossRef] [PubMed]

58. Ponpium, P.; Ratanakhanokchai, K.; Kyu, K.L. Isolation and properties of a cellulosome-type multienzyme complex of the thermophilic bacteroides sp. Strain p-1. Enzyme Microb. Technol. 2000, 26, 459-465. [CrossRef]

59. Weiss, S.; Tauber, M.; Somitsch, W.; Meincke, R.; Muella, H.; Berg, G.; Guebitz, G.M. Enhancement of biogas production by addition of hemicellulolytic bacteria immobilised on activated zeolite. Water Res. 2010, 44, 1970-1980. [CrossRef] [PubMed]

60. Jiménez, D.J.; Korenblum, E.; van Elsas, J.D. Novel multispecies microbial consortia involved in lignocellulose and 5-hydroxymethylfurfural bioconversion. Appl. Microbiol. Biot. 2014, 98, 2789-2803. [CrossRef] [PubMed]

61. Penner, T.J.; Foght, J.M.; Budwill, K. Microbial diversity of western canadian subsurface coal beds and methanogenic coal enrichment cultures. Int. J. Coal Geol. 2010, 82, 81-93. [CrossRef]

(C) 2017 by the authors; licensee MDPI, Basel, Switzerland. This article is an open access article distributed under the terms and conditions of the Creative Commons Attribution (CC BY) license (http:/ / creativecommons.org/licenses/by/4.0/). 